\title{
Dispositivos móveis digitais e competências para a utilização na "sociedade do conhecimento"
}

\author{
Digital mobile devices and skills to use in the "knowledge society" \\ María Carmen Ricoy / cricoy@uvigo.es \\ Maria João Valente da Silva Couto / mjoaocouto@uvigo.es \\ Universidade de Vigo, Espanha
}

\begin{abstract}
The work presented here is intended to identify the mobile digital devices which Spanish university students rely on, as well as analyze the skills they deem necessary for their use in today's society. The part of the investigation addressed here fits the qualitative approach, from the reports of students who attended Social Education Degree at the University of Vigo. As conclusions is to highlight the everyday use that students take the laptop and the mobile phone in the academic, personal and social context. In and attenuated form they use the digital camera, game consoles, e-books, smartphones and tablets. To benefit from these devices and to successfully meet the challenges of the knowledge society they consider it necessary to mainly develop the competence to solve problems, search for information, communication, personal autonomy and sharing.
\end{abstract}

Key words: knowledge society; information and communication technologies; mobile digital devices; skills; higher education.

Resumo: O trabalho que se apresenta tem como finalidade identificar os dispositivos móveis digitais aos quais recorrem os alunos universitários espanhóis, assim como analisar as competências que consideram necessárias para a sua utilização na sociedade contemporânea. A parte da investigação aqui abordada enquadra-se no enfoque qualitativo, a partir dos relatos de estudantes que frequentavam a Graduação de Educação Social na Universidade de Vigo. Como conclusões é de destacar o uso quotidiano que os alunos fazem do computador portátil e do telemóvel no âmbito académico, pessoal e social. De forma atenuada utilizam a câmara fotográfica digital, as consolas de jogos, o ebook, o smartphone e o tablet. Consideram que para beneficiarem destes equipamentos e enfrentarem com sucesso os desafios da «sociedade do conhecimento» é necessário desenvolverem principalmente a competência de resolução de problemas, de procura de informação, comunicativa, autonomia pessoal e partilha.

Palavras-chave: sociedade do conhecimento; tecnologias da informação e comunicação; dispositivos móveis digitais; competências; educação superior. 


\section{Introdução}

A diversidade de aparelhos digitais móveis existente no mercado e o uso que os cidadãos já fazem deles colocam em relevo o espetro de possibilidades que oferecem, tanto no plano pessoal como no académico, social e laboral. Atualmente, na chamada «sociedade do conhecimento» a informação e, por conseguinte, o conhecimento evoluem a um ritmo vertiginoso. Para Villavicencio et al. (2012) a «sociedade do conhecimento» faz referência à propensão de gerar, assimilar e difundir o saber com o fim de impulsar a inovação e o desenvolvimento socioeconómico dos países. Assim, é de reconhecer com Almeida e Freire (2012) a importância que tem na sociedade contemporânea a aquisição de competências para o uso das Tecnologias da Informação e Comunicação (TIC). Tendo em conta que a instituição escolar é um instrumento fundamental para incorporar as pessoas na vida social (García-Lastra, 2013), há ainda que considerar as etapas de formação pós-obrigatória pela repercussão para o exercício de uma cidadania ativa e o contributo para o mundo laboral.

$\mathrm{Na}$ atualidade o acesso ao conhecimento e à informação deixa de estar restringido a espaços físicos concretos: escolas, universidades, bibliotecas, etc. Este fato coloca desafios e oferece grandes possibilidades para a cidadania e aos contextos de formação. Em particular, no caso de Espanha, perante as novas exigências apresentadas pela adaptação da docência ao Espaço Europeu de Educação Superior (EEES). Neste marco, o aluno universitário deve coresponsabilizar-se pelo próprio ritmo de trabalho e aprendizagem e cabe ao professor orientá-lo no percurso formativo. Por outra parte, neste contexto, tendo em consideração a polivalência das TIC, o desenvolvimento das competências transversais é enquadrado nas diferentes matérias dos planos de estudo das Graduações e Mestrados universitários.

Em Espanha a Agência Nacional de Avaliação da Qualidade e Acreditação (ANECA) (2005), responsável por verificar as memórias dos curricula da educação superior, sustém que as TIC são instrumentos que se utilizam para a comunicação, o acesso, gestão e difusão da informação. Além disso, reconhece que constituem ferramentas úteis para a promoção do trabalho cooperativo, a aquisição de novas aprendizagens ao longo da vida e o desenvolvimento das relações sociais, do ócio e da investigação. Nesta linha, tem sentido que os estudantes se formem para o uso das novas tecnologias e tendo em consideração que é preferivel saber como se localiza a informação, em lugar de abusar da excessiva memorização de conteúdos. 
As TIC estão a transformar as infraestuturas, as metodologias didáticas e a interação a partir de comunidades virtuais de aprendizajem, mudando as organizações milenares de ensino. A informação já não é domínio de minorias e está associada tanto ao espaço físico como ao ciberespaço. Desta forma, a aprendizagem torna-se cada vez mais móvel. De facto, a emergência do paradigma sobre a educação ubíqua deriva do proveito obtido a partir das potencialidades e possibilidades que a Internet oferece, através dos dispositivos móveis, em qualquer momento e parte do mundo. Cope e Kalantzis (2009) vão mais além e sustêm que o extraordinário desenvolvimento da tecnologia faz com que a aprendizagem omnipresente não seja tão somente uma certeza, tendo-se já convertido num imperativo social, em especial entre as jovens gerações. Adicionalmente, Tait (2013) defende que não se pode encarar a educação unicamente como uma finalidade em si mesma, senão como um conjunto de atividades que brindam com outros resultados as pessoas e as sociedades, entendendo que propicia ou trava o progresso dos cidadãos, a partir do que pode e deve contribuir para a capacidade humana.

Uma verdadeira transformação requer processos de inovação didática, de novos referentes e modelos administrativos de gestão de conhecimento pelos docentes e ao redor das relações construídas por estes com os seus estudantes (Said-Hung, 2012). Neste sentido, desde o sistema educativo, os governos têm que dar resposta às demandas profissionais e da cidadania com o objeto de satisfazer as suas necessidades e preparar para afrontar os desafios permanentes que se lhe apresentam numa sociedade globalizada. Por tudo isto, é de ressaltar que resulta imprescindivel contar com o desenvolvimento, entre outras, da competência digital, para poder viver na sociedade contemporânea.

O termo «competência» expressa a capacidade ou o potencial de uma pessoa para atuar de maneira eficiente em situações similares. Contudo, mais do que o domínio de uma aprendizagem teórica estática ou de um saber específico, as competências são um processo dinâmico em constante desenvolvimento (Raynal e Rieunier, 1998). Para Calvani et al. (2012) o espetro da digitalização é muito amplo. De tal forma que abrange desde as competências que exigem a manipulação técnica até às que incluem múltiplos conhecimentos (que integrem habilidades, destrezas e outras capacidades complexas), capacidades relacionadas com a procura, seleção, organização e compreensão da informação e com a de comunicação, colocando em funcionamento dimensões cognitivas de nível elevado.

Ao contrário das competências específicas, as de tipo transversal ou genérico não estão associadas a uma única disciplina académica e título 
universitário. Este é o caso das de índole digital que não são próprias de uma só titulação, nem sempre se centram num tipo de conteúdo muito específico. Ou seja, são básicas e comuns a múltiplas disciplinas curriculares. Por este motivo, nos planos de estudo das instituições espanholas de ensino superior, entre outras, consideram como competências transversais as que requerem a utilização das TIC. Este facto justifica-se pela versatilidade das tecnologias e a sua aplicabilidade em inúmeras situações.

Bergaud et al. (2012) assinalam resistências, entre as exigências da «sociedade do conhecimento» e as competências requeridas, para atuar no contexto social e para competir no mercado laboral. Tudo isto, independentemente de se considerar que representam um papel determinante na adaptação aos processos de mudança. No entanto, no momento atual pode existe ainda um défice de competências nos jovens, apesar da visão popular tender a designá-los como «nativos digitais» sem verdadeiramente o serem (Livingstone et al., 2011). Para combater esta situação, possivelmente promotora da fenda digital pela criação de contextos de exclusão social, reveste especial importância o papel das instituições de ensino e dos seus profissionais. Neste sentido, há que trazer à colação que, por agora, são insuficientes os conhecimentos desenvolvidos no âmbito educativo, capazes de dotar os estudantes universitários com as competências digitais apropriadas, para enfrentar com êxito a participação nas atividades cívicas e para assumir as futuras responsabilidades no mundo do trabalho (Cózar e Roblizo, 2014; Gvaramadze, 2012).

Sobre o desenvolvimento de ativividades inovadoras com o uso das TIC, tem especial incidência o tipo de praxis promovida pelos professores e as infraestruturas e serviços disponibilizados: equipamentos informáticos, Wi-fi, tomadas de corrente, mobiliário apropriado e assistência técnica para pessoal docente e alunos. Contudo, ensinar e aprender exige flexibilidade, espaço e tempo, pessoalmente e em grupo, menos conteúdos fixos, processos abertos de formação, investigação e comunicação (Moran, 2010). Independentemente das mudanças e desafios gerais associados às TIC a sua constante evolução ou emergência nem sempe supõe uma imediata repercussão nos cidadãos, nem plasma veemente efeitos ou inovações pedagógicas (Duart, 2011). De facto, é habitual reproduzir velhas estratégias com o uso de novos recursos tecnológicos (Area, 2010; Sánchez-Antolín et al., 2014). Portanto, a utilização da tecnologia, em si mesma, não assegura a incorporação de práticas didáticas inovadoras.

Enquanto à linha de investigação aqui abordada, que se enquadra na metodologia qualitativa, a de maior tradição sobre as TIC é a ligada com 
a educação escolar, sendo a sua materialização no contexto universitário menor. Adicionalmente, os estudos existentes sobre o uso e aplicabilidade incluindo os dispositivos móveis digitais são ainda escassos (Kobus et al., 2013). Assim sendo, é pertinente indagar, especificamente nesta linha, desde o contexto universitário. Deste modo, o presente trabalho tem um maior interesse partindo dos reduzidos estudos que se têm desenvolvido o enfoque qualitativo (Gómez Gonzalvo, 2014).

Com o presente estudo pretende-se identificar os dispositivos móveis digitais utilizados pelos estudantes da educação superior e a sua aplicação nos planos académico, pessoal e social; analisar as competências que consideram necessárias para a aplicação destes recursos na sua formação, no quotidiano (como meio de relação e ócio) e com vista ao futuro profissional; e revelar a relação que estabelecem entre o uso dos dispositivos e as competências necessárias e destas entre si.

\section{Metodologia}

Esta investigação forma parte de uma mais ampla ${ }^{1}$ que se desenvolve, no seu conjunto, a partir de uma perspetiva mista (quantitativa-qualitativa). Pela restrição de espaço, própria de um artigo científico, o trabalho aqui apresentado centrou-se numa parte enquadrada no enfoque qualitativo. Esta metodologia permite aprofundar na análise de uma realidade, a partir de um contexto, com as suas práticas e dentro da particularidade e complexidade que representa o grupo objeto de estudo. Seguindo Yin (2009), as unidades de análise determinadas de acordo com os objetivos definidos permitem demarcar os limites do caso, através das argumentações disponibilizadas pelos participantes. Esta investigação é de tipo narrativo (narrative inquiry) desenvolveu-se a partir dos relatos de um grupo de estudantes universitários.

1 Este trabalho enquadra-se num projeto de investigação ambicioso sobre os dispositivos móveis digitais e o desenvolvimento de competências (ref.: EDU2010-17420).É financiando pelo «Ministerio de Educación, Cultura y Deporte» do Governo de Espanha (2010-2014). Trata-se de um projeto interuniversitário que se aborda dentro do contexto universitário espanhol. A sede da direção esteve localizada na «Universidad Nacional de Educación a Distancia» (Madrid-Espanha). A equipa de investigação compõe-se de doze docentesinvestigadores de cinco universidades espanholas: «Universidad Nacional de Educación a Distancia » (7 investigadores); «Universidad Complutense de Madrid» (1 investigador); «Universidad de Granada ( 1 investigador); «Universidad de Oviedo» (2 investigadores); e «Universidade de Vigo» (1 investigadora). 
Concordando com Hargreaves (1998), a narrativa constitui uma forma de contar e reconhecer a própria história e vivências pessoais. Portanto, consiste num modo de pensar reflexivamente e de organizar as recordaçóes, a informação, as experiências e as crenças supondo um meio excelente para conhecer a realidade, a partir do protagonismo dos participantes.

\section{Elaboração do instrumento para a recolha da informação}

Inicialmente, elaborou-se um guião ad hoc para solicitar aos alunos da educação superior a produção dos seus relatos, com a finalidade de responder aos objetivos definidos para esta parte do estudo. $\mathrm{O}$ enunciado da questão, a responder com as narrativas, foi precedido da solicitação dos dados de identificação pessoal, com a garantia da proteção dos mesmos. Adicionalmente, refira-se que o seu texto foi apresentado aos participantes com uma certa abertura, para que a flexibilidade promovesse uma narração extensiva e se pudesse originar a descrição e reflexão em profundidade sobre o foco objeto da investigação.

Para validar o instrumento de recolha de informação recorreu-se ao juízo de peritos. Submeteu-se o enunciado da questão inicial do relato à análise de cinco docentes universitários e investigadores (três mulheres e dois homens). A seleção destes doutorados realizou-se considerando o seu grau de competência científica, a proximidade com a temática de estudo, o coletivo em causa e o conhecimento que possuem deste tipo de técnica de recolha de informação. Posteriormente, a partir dos seus comentários ou sugestões construiu-se a redação final da questão do relato. Assim, propôsse o seguinte enunciado: Indica os dispositivos móveis digitais que utilizas e comenta as competências (capacidades, habilidades, procedimentos, atitudes, etc.) que consideras necessárias para o seu uso na «sociedade do conbecimento», com vista ao teu desenvolvimento académico, pessoal e social, assim como para encaminhá-las para o desempenho da tua futura profissão.

\section{Procedimento de recolha e análise dos dados}

A recolha da informação foi impulsionada, a partir da sala de aula, pela professora que é coautora deste artigo e membro do projeto de investigação já referido. A temporalização definida em consenso com os participantes, para desenvolver o relato de forma autónoma e individual, foi de 60 minutos. Estas narrativas foram realizadas pelos alunos no final do ano 2011 (mês de novembro), em suporte digital, num processador de textos selecionado 
livremente. Posteriormente, a partir das indicações disponibilizadas, as narrativas foram transferidas pelos alunos para os seus respetivos e-portfólios, localizados na plataforma de teleformação da Universidade de Vigo.

Uma vez adaptado o formato dos textos e sucessivamente importados pelas investigadoras responsáveis para o programa informático de Analysis of Qualitative Data (AQUAD) na versão 6.0, procedeu-se à análise de conteúdo. Para estas análises extraem-se das narrativas categorias que representam ideias substanciais, a partir do relacionamento entre os objetivos definidos e a informação recolhida (Yin, 2005). Desta forma, foi possível utilizar um sistema de codificação categorial (primeiro nível) e subcategorial (segundo nível) que permite aprofundar nos dados. As categorias principais ou de primeiro nível, apresentam-se como enunciado de cada subepígrafe dos resultados. As subcategorias estabeleceram-se a partir de núcleos de informação com sentido que permitem identificar unidades relevantes de análise. Com este procedimento reduziram-se os textos em bruto, obtendose categorias de primeiro e segundo nível, das quais se determina o seu grau de preponderância ou singularidade.

Uma vez que o software utilizado permite realizar a contagem das frequências das subcategorias e exportá-las para o programa Excel, foi possível elaborar figuras e tabelas onde se expõe os resultados, cruzandoas adicionalmente. $\mathrm{O}$ cômputo é ilustrativo da tendência ou singularidade subcategorial produzida. Contudo, tratando-se de um estudo qualitativo, a referida quantificação não tem a finalidade de enfatizar esta faceta. De facto, seguindo Tierney (2012), só é possível adquirir a compreensão dos dados através da vertente qualitativa da análise.

É de referir que a fiabilidade dos resultados obtidos está garantida pela sistematização seguida no desenvolvimento do processo de análise e à exatidão registada pelo programa informático utilizado. Seguindo Yin (2005) a existência de um protocolo de estudo está relacionada com a organização dos dados e com a sua fiabilidade. Além disto, como foi refletido, planificou-se o procedimento para a construção do instrumento de coleta da informação, estruturou-se e tutelou-se a recolha no grupo de participantes e disponibilizam-se evidências consistentes sobre o desenvolvimento da análise de conteúdo (Hernández et al., 2006).

\section{Participantes}

Para incentivar a participação, na produção da informação, os alunos foram informados pela docente, e já referida investigadora, sobre os objetivos e 
interesse que possui o tópico objeto de estudo. No total, para esta parte do estudo, foi possível envolver 55 estudantes no primeiro ano da Graduação de Educação Social na Faculdade de Ciências da Educação da Universidade de Vigo (Espanha), estando associados ao ano letivo 2011/2012. A partição por sexos não é equilibrada (6 alunos e 49 alunas). Contudo, é justificada pela composição inicial do grupo-aula. As idades dos participantes estavam compreendidas entre os 18 e os 37 anos, com uma média de 21 anos.

Como pode deduzir-se do posicionamento exposto, para a seleção da amostra foram utilizados critérios de acessibilidade aos alunos. De modo que o seu envolvimento foi promovido a partir da relação e a empatia da docenteinvestigadora com o grupo e beneficiado da gentileza apresentada pelos implicados. Trata-se portanto de uma amostra em condições propícias para a recolha da informação. Esta abordagem, típica dos estudos de caso, tal como afirma Yin (2009), permite investigar um fenómeno contemporâneo no seu contexto real, economizando meios e tempo aos investigadores.

\section{Resultados}

Sobre os resultados é oportuno indicar primeiramente que se extraem quatro dimensões de análise, a partir dos objetivos refletidos e tendo também em consideração a informação recolhida. Estas categorias, que se enunciam de seguida, configuraram os núcleos principais de dados (categorias de primeiro nível):

a) Dispositivos móveis digitais utilizados pelos alunos.

b) Competências necessárias para a utilização dos equipamentos móveis digitais (âmbito académico, pessoal, social e com vista ao desempenho profissional futuro).

c) Associação e correspondência estabelecida entre as competências e o uso dos aparelhos móveis digitais.

Nas diferentes epígrafes aprofunda-se na compreensão e interpretação dos dados procedentes das subcategorias e disponibilizam-se alguns excertos para enriquecer a compreensão dos resultados expostos. Estes fragmentos das narrativas são acompanhados com o número atribuído para a análise de cada relato, a identificação do género do participante e a sua idade (Exemplo: $R_{1}$, feminino, 22 anos). 


\section{Uso dos dispositivos móveis digitais}

Os dispositivos móveis (com e sem acesso à Internet) utilizados pelos alunos são o: computador portátil, telemóvel, câmara fotográfica digital, consola de jogos (adiante designada também por consola), leitor de ebook (ou referido como ebook), MP3, rádio, smartphone e tablet (Figura 1). Entre eles destacamse o portátil e o telemóvel, pelo número de vezes que se faz referência à sua utilização e a amplitude imputada à sua aplicabilidade. Há que sublinhar a importância acentuada que os participantes atribuem a ambos os recursos (ver Figura 1). ${ }^{2}$

Em particular, o computador portátil é o dispositivo móvel mais utilizado pelos alunos. Geralmente associam-no com a pesquisa de informação e com a produção de conteúdos dirigidos pelos docentes universitários para a concretização de atividades formativas. Manifestam de forma expressiva que dispõem de conexão à Internet em casa e/ou na universidade e que isto lhes permite aceder rapidamente e com grande liberdade aos recursos disponibilizados na rede. Além disso, consideram que as inúmeras vantagens da web estão relacionadas com a difusão da informação, a diminuição de limitações espaço-temporais e as facilidades para a criação e a edição de conteúdos.

O portátil é descrito pelos estudantes como um aparelho de fácil manejo, nomeadamente por dispor de um ecrã com dimensão suficiente para não exigir esforços visuais e de psicomotricidade fina importantes. Adicionalmente, também entendem que lhes permite realizar comodamente tarefas que pressupõem um trabalho prolongado, concretamente para a introdução manual de conteúdos que lhes possibilita levar a cabo práticas complexas. De facto, ainda que muitos dos telemóveis dos participantes disponham de teclados QWERTY, eles entendem que o tamanho mais reduzido destes é útil ou adequado para atividades nas quais se necessite da digitação rápida e/ou pontual de dados e/ou comandos (procura de informação ocasional, envio de mensagens, etc). Qualificam como bastante penoso o seu uso para atividades de criação de documentos, folhas de cálculo, etc. De modo ilustrativo vejase o excerto seguinte: $O$ dispositivo móvel de novas tecnologias que mais uso e sobre o que vou falar maioritariamente é o portátil. Posso dizer que comecei a utilizar este dispositivo móvel com mais frequência este ano para a procura de informação nas distintas matérias na universidade e para a realização de trabalhos diversos $\left(\mathrm{R}_{33}\right.$, masculino, 22 anos).

2 Todas as figuras e tabelas estão localizados em anexo, no final deste artigo (Notal Editor). 
Como alternativa aos anteriores equipamentos, os participantes fazem referência ao tablet. Contudo o seu uso é mais limitado. Ainda que este aparelho reúna distintas possibilidades dos portáteis, sentem a falta de mais algumas caraterísticas ou funções essenciais. Oferece-se algum exemplo a respeito: [...]. Por último, uso também o tablet mas, menos vezes já que não se aplica tanto. De vez em quando utilizo-o para ler ( $\mathrm{R}_{7}$, feminino, 19 anos).

Os alunos declaram que fazem um uso esporádico da câmara de fotos digital e da consola. Contudo, descobre-se o interesse de diferentes participantes pela partilha de fotos e/ou vídeos junto dos seus pares, em particular com a frequência manifestada nas descargas a partir das redes sociais. Referem que armazenam as imagens/áudios recolhidas(os) através dos dispositivos digitais comummente associados para este fim e, segundo lhes convenha, publicam-nos na «nuvem». De modo ilustrativo, depreendese este uso ocasional no seguinte texto: Os dispositivos móveis que mais uso são o computador portátil e o telemóvel. Também posso incluir a câmara de fotos porque a utilizo de vez em quando, sobretudo no meu tempo livre ( $\mathrm{R}_{3}$, feminino, 19 anos).

A partir dos dados obtidos fica evidente que é prática usual dos estudantes a divulgação na Internet de conteúdos relacionados com a sua vida quotidiana, em particular através das redes sociais. Plasmam que deste modo também geram aprendizagens, ainda que de forma autónoma e informal. Consideram que este facto é consequência direta do atual dinamismo da web 2.0, que permite a qualquer usuário integrar-se facilmente nas comunidades virtuais e ligar a atividade académica com a sociopessoal e laboral. Salientam que as interações originadas na sequência desta praxis não estão restringidas por questóes de tempo e espaço, enquanto que na esfera física assim sucede. Como negativo, aludem à dependência que podem chegar a gerar nos usuários.

Particularmente no que diz respeito à consola de jogos, há a indicar que é um equipamento pouco utilizado pelos participantes. Contudo, consideramna com alguma relevância como meio para a relação entre as pessoas com interesses muito específicos. Referem que com o seu uso são treinadas competências encaradas como benéficas também para a futura atividade profissional, como a de: cooperação, estratégia, superação/ambição, etc. Outros há que lhe atribuem a este equipamento um potencial didático, tanto em contextos académicos formais, como em situações informais. Uma aluna dá testemunho do seu uso no seguinte parágrafo: [...] utilizo as consolas no meu tempo livre porque têm jogos com os quais aprendo e me divirto. Como consequência melhoram a minh a destreza e aprendo coisas, pois qualquer pessoa 
aprende mais rápido através do jogo do que na educação regulamentada com livros, aulas magistrais, etc. ( $\mathrm{R}_{17}$, feminino, 23 anos).

Os restantes recursos que utilizam (ebook, MP3, rádio, smartphone e tablet) são referidos por um número reduzido de estudantes (inferior a cinco alunos). A informação obtida sobre os pormenores da sua aplicação reflexa o emprego fundamentalmente na prática de ócio para a: leitura de livros (ebook), escuta de música (MP3 e rádio), realização de chamadas, consulta de correio eletrónico, agenda e elaboração de fotos (smartphone e tablet).

\section{Competências necessárias para o uso dos dispositivos móveis}

Os participantes consideram que a utilização dos equipamentos móveis digitais, além de lhes permitir recorrer a uma grande diversidade de recursos e oferecer-lhes múltiplas oportunidades na «sociedade do conhecimento», exige-lhes o desenvolvimento de diversas competências. Alguns indicam que esta necessidade torna-se premente no processo de ensino, sob pena das TIC não cumprirem a sua missão educativa genérica, social e de formação para o percurso laboral. Com boa lógica percebem que têm que formar-se para a vida quotidiana, não descuidando o manejo das ferramentas digitais. Por isto, revelam que as instituções de ensino superior, mais que nenhuma outra, deve dotá-los das competências necessárias (ver Figura 2).

Os estudantes argumentam que é fundamental dispor de fluidez digital para usar os dispositivos móveis (Figura 2). Enfatizam as competências que se referem à resolução de problemas, procura de informação, comunicação e autonomia. Além destas, alguns participantes também indicam como de interesse as associadas com a: abertura; autocontrole; partilha; criatividade; gestão de recursos; realização de juízos críticos; domínio linguístico (em particular do idioma inglês); manejo técnico; motricidade fina; persistência e prudência.

Da análise realizada, depreende-se a importância atribuída pelos estudantes à capacidade de resolução de problemas, na medida em que consideram que lhes permitirá enfrentar com sucesso os desafios profissionais futuros. Entendem que a competência passa pelo reconhecimento de situações problemáticas e a capacidade para aplicar estratégias adequadas para solucioná-las. Esta aptidão para superar barreiras e enfrentar os desafios é considerada como essencial pelos alunos para atuar quotidiana, académica e profissionalmente. Através do conjunto de evidências manifestam a sua tranquilidade para afrontar a resolução de problemas, principalmente de 
tipo técnico, originada pelo manejo que fazem dos distintos equipamentos. Neste sentido, alguns revelam uma postura descontraída, tendendo a não problematizar as situações menos favoráveis. Há participantes que perante maiores adversidades, derivadas da utilização dos recursos móveis digitais, tendem a delinear mecanismos para encontrar uma solução.

Os estudantes assumem que o emprego dos dispositivos móveis digitais passa pelo empenho, a motivação e o esforço individual para ultrapassar com sucesso os obstáculos detetados e enfrentar com determinação os desafios presentes e futuros. Neste sentido, veja-se o excerto: As competências, conhecimentos e outros aspetos que considero necessários para resolver os problemas que encontro com o uso dos dispositivos móveis digitais são: a motivação, o encontrar alternativas, o ser atrevida e não temer o erro, tentar e tentar, à procura das novidades, o empregar novos dispositivos que me tragam vantagens e não entraves, a formação autodidata, a tentativa erro e a informação recolhida de outras pessoas para a resolução dos meus problemas $\left(\mathrm{R}_{47}\right.$, feminino, 24 anos).

A procura de informação constitui outra das competências reconhecidas como fundamental pelos alunos universitários, para contar com a fluidez digital necessária, em particular no trabalho com materiais didáticos. $\mathrm{Na}$ medida em que dispõem de possibilidades para a conexão normalizada à Internet, também consideram que é fulcral saber pesquisar, organizar e produzir informação de acordo com as necessidades, problemas e contextos que lhe são próximos pessoal, académica, social e profissionalmente. Evidenciam a importância atribuída à produção e divulgação de conteúdos de qualidade, associando-as a questões de tipo prático. Ressaltam o facto de que todos possam criar informação e partilhá-la com os demais.

Por outra parte, os estudantes referem a capacidade comunicativa para a utilização dos dispositivos móveis digitais. Destacam a sua relevância como meio para favorecer e potenciar a relação em comunidade e entre colegas e professores. Nos seus discursos englobam aspetos muito diversos: saber utilizar diferentes formas de comunicação, adequar o código linguístico aos múltiplos contextos, enriquecer a interação verbal e não verbal (com diferentes recursos) nos cenários digitais. Uma aluna plasma a respeito esta reflexão: No começo do novo milénio e com a Internet pode dizer-se que para mim iniciou-se a «sociedade do conbecimento». Uma vez adaptados a ela, o próximo passo para nós é participar verdadeiramente num espaço universal de comunicação, no qual se poderá partilhar e gerir a informação para convertê-la em conbecimento ( $\mathrm{R}_{6}$, feminino, 18 anos). 
Os alunos reconhecem a grande evolução operada nos equipamentos e a diminuição dos custos associados às tarifas da comunicação telefónica e/ ou de acesso à Internet. Na sua opinião, este facto contribui muito para a promoção do dinamismo caraterístico da «sociedade do conhecimento», assim como para o desenvolvimento saudável da competência comunicativa através do ciberespaço.

Outra competência referida como necessárias para a utilização dos dispositivos móveis é a da autonomia pessoal. Os participantes entendemna como a capacidade de gerir o próprio comportamento e atuações para adotar posturas personalizadas capazes de construir, dirigir e perspetivar o seu processo de formação e maduração, assim como para o exercício de direitos e deveres como cidadãos. Concordam que estas capacidades e as suas especificidades caraterizam-se pela importância atribuída ao próprio indivíduo e à independência face a outras pessoas. Com o seguinte texto ilustra-se uma parte do percurso de um aluno: No meu caso considero essencial para o uso dos dispositivos móveis digitais uma série de habilidades e capacidades tecnológicas que fui adquirindo ao longo dos anos mediante cursos de mecanografia e informática, com conversas com outras pessoas, experiências e alguma procura ou pesquisa individual ( $\mathrm{R}_{32}$, masculino, 19 anos).

A competência sobre o juízo crítico associa-se com a possibilidade de análise de conteúdo e a sua valoração e apropriação. Isto porque os alunos consideram que lhes permite construir opinião, basicamente usando o raciocínio, a partir de assuntos reais ou de fácil compreensão. No seu entender, é possível um conhecimento efetivo e estimulante, em contextos formais e informais de aprendizagem, pelo uso frequente das TIC e, em especial, dos dispositivos móveis. Veja-se a perceção de uma estudante a respeito: $O$ mais importante é ser capaz de selecionar a informação, escolher a mais adequada numa página web segura que contenha conteúdo fidedigno ou pelo menos credivel. O maior problema dos dispositivos móveis e das TIC em geral é que qualquer pessoa pode divulgar as suas ideias ou pensamentos, sem nenhum nivel deprofundidade e sem que sempre sejam avaliados ou corrigidos por especialistas. Por isso, é fundamental ter uma atitude crítica perante os conteúdos expostos na rede e há que consultar várias páginas sobre a mesma temática, que procedam de fontes distintas, com o fim de comparar a informação que se quer usar com rigor $\left(\mathrm{R}_{48}\right.$, feminino, 22 anos).

No que se refere à competência criativa, associada com as TIC, os estudantes entendem que consiste na capacidade de originar ou inventar para produzir algo novo e singular. Recorrendo às possibilidades da tecnologia 
(câmara fotográficas digitais, telemóvel com câmara integrada, etc) consideram que se torna bastante apelativo desenvolver algumas habilidades artistas no âmbito da fotografia. Por outra parte, a facilidade em tornar públicas as imagens e vídeos incentiva os implicados, ao poder recordar momentos agradáveis e partilhá-los, principalmente através das redes sociais, com pessoas conhecidas e desconhecidas.

Também a competência técnica ou instrumental, que ligam plenamente à praxis, é referida como valiosa para a utilização dos dispositivos móveis. São conscientes que na sociedade contemporânea, mais além da alfabetização tradicional, é um problema não estar alfabetizados digitalmente. Os participantes consideram, coincidindo com os especialistas, a competência em TIC como o conjunto de procedimentos, destrezas, habilidades, capacidades, atitudes, valores, etc, que está fortemente condicionada pelo nível de manejo técnico dos aparelhos, sem que se resuma a isto. Independentemente que apontem nas narrativas que os avanços tecnológicos exigem que os usuários saibam manipular tecnicamente os aparelhos mais atuais, para tirar proveito dos recursos disponibilizados digitalmente. Entendem a competência técnica como transversal na utilização dos equipamentos tecnológicos. Adicionalmente percebem-na também como substancial para o desenvolvimento académico, pessoal, social (fundamentalmente como meio de relação ou interação) e para o desempenho da futura profissão.

A importância atribuída à competência linguística está presente nos textos apresentados por alguns alunos. Associam-na principalmente ao domínio do código verbal escrito, em particular por a entenderem necessária à compreensão de conteúdo e para comunicarem através dos dispositivos. Além disso, incidem especialmente na importância que supõe o domínio do idioma inglês para navegar pela Internet e utilizar diferentes aplicações digitais. Outros participantes são da opinião que é necessário desenvolver habilidades comunicativas transversais a diversos aparelhos. De tal forma que elas, por exemplo, lhe permitam digitar uma mensagem para poder transmitir tudo o que desejarem.

Por outro lado, consideram fundamental continuar a manter e aperfeiçoar o domínio das habilidades linguísticas nativas (principalmente escritas), de tal forma que as más práticas não os conduzam ao esquecimento das formas corretas de escrita. De modo ilustrativo disponibiliza-se o seguinte excerto: Utilizo tanto o telemóvel que, sem querer, às vezes dou-me conta que escrevo com falhas de ortografia por culpa das mensagens (claro exemplo: 0 « $x \gg$ em vez de «por» ou 0 «q» em vez de «que»...). Quem utiliza frequentemente 0 telemóvel, o que faz é escrever abreviaturas para poupar tempo. É importante 
María Carmen Ricoy y Maria João Valente da Silva Couto. Dispositivos móveis digitais e competências para a utilização na "sociedade do conhecimento"

escrever rápido, mas não podemos perder a noção de como escrever corretamente $\left(\mathrm{R}_{50}\right.$, feminino, 19 anos).

Associação entre o uso dos dispositivos e as competências, e correspondência

Das análises realizadas deriva a ligação que os participantes estabelecem entre os dispositivos móveis digitais que utilizam e as competências que lhes são requeridas, para enfrentar com sucesso os desafios da «sociedade do conhecimento». Para distintos equipamentos foi possível identificar a ligação implícita entre competências. A incidência de cada uma das subcategorias (por dispositivo e competência) coloca em destaque o tipo de exigências que atribuem a cada dispositivo (ver Tabela 1 ).

Os resultados obtidos deixam em relevo (célula assinaladas a preto, Tabela 1) a tendência dos alunos em associar, principalmente ao portátil e ao telemóvel, a competência de procura de informação, a comunicativa e a de resolução de problemas.

Através dos seguintes textos pode conhecer-se a perceção manifestada por uma aluna:

Graças ao portátil e ao telemóvel tenho a possibilidade de comunicar com quem quiser (normalmente com amigos elou familiares) e posso fazê-lo de diversas formas. É importante conhecer e saber utilizar diferentes funçóes para: chamadas telefónicas; videochamadas; e escrever mensagens ou enviar correios eletrónicos para qualquer lugar do mundo. Isto porque no futuro quem não estiver atualizado terá menos possibilidades de ter sucesso. O telemóvel, além da comunicação, permite-me estabelecer uma conexão com a Internet, tirar fotografias como se de uma câmara fotográfica se tratasse e escutar música tal como com o MP3. Tudo isto, tenho a certeza que contribui para o meu desenvolvimento integral ( $\mathrm{R}_{19}$, feminino, 20 anos).

Dos discursos dos participantes depreende-se uma propensão acentuada (célula assinaladas a cinzento escuro, Tabela 1) por relacionar o portátil e o telemóvel com as competências de abertura, autonomia e partilhar simultaneamente. Do que se deduz que entendem a importância que supõe a sua combinação para o desenvolvimento de determinadas práticas. A respeito, uma estudante plasma uma parte das suas ideias no parágrafo em diante: Graças o portátil e ao telemóvel podes ampliar a tua formação através de cursos online, consulta de páginas web sobre temas novos e curiosos. É interessante, a partir de um posicionamento de abertura, a participação e o intercâmbio de opiniöes, por exemplo em distintos fóruns. Além disso, sempre se pode partilhar 
informação disponivel e inclusivamente a resolução de dúvidas sobre algum aspeto, ainda que seja necessário ser decidida e perder a timidez $\left(\mathrm{R}_{31}\right.$, feminino, 20 anos).

A partir da análise realizada também foi possível descobrir a associação que estabelecem os alunos entre as competências necessárias para o uso dos aparelhos móveis digitais. Os resultados oferecem evidências que revelam a inter-relação estabelecida entre diferentes competências na utilização destes recursos (ver Tabela 2).

Os estudantes enfatizam a correspondência entre a competência de resolução de problemas, a de procura de informação e a comunicativa (células assinaladas com fundo em negro, Tabela 2). Com distintas razões argumentam a importância atribuída à ligação existente nas competências, colocando em destaque a relação das mesmas ou a sua complementaridade. De forma ilustrativa veja-se o seguinte excerto: Para mim o telemóvel permite numerosas formas de aprendizagem, dai que seja preciso saber bem como funciona. Claro que é necessário ter o minimo de competências para comunicar através dele. As vezes épreciso pedir explicaçóes ou resolver alguma dúvida que se tenha no curso $e$, para isto, usando-se normalmente o telemóvel solucionam-se rapidamente os problemas. Podemos utilizá-lo em qualquer lugar ou a qualquer hora, basta que haja suficiente cobertura e a bateria esteja carregada. Como qualquer pessoa já pode ter telemóvel com Internet, também pode procurar informação em qualquer momento do dia. Só temos que saber encontrar a informação certa $\left(\mathrm{R}_{2}\right.$, feminino, 19 anos).

Os resultados também põem em destaque uma conexão acentuada entre a competência de procura de informação com a de: abertura, autonomia, partilhar, comunicativa, motriz e prudência. Além disso, os alunos tendem a referir, em simultâneo, nos seus relatos, o ser prudente e autónomo (células assinaladas com fundo cinzento escuro, tabela 2). Do mesmo modo, relacionam a competência sobre resolução de problemas com a de abertura, autonomia, partilhar e prudência. Uma aluna reflete: [...] a informação a que se term acesso pela Internet nem sempre é verdadeira. Por isso, creio que sobretudo é necessário ter cuidado, ser prudente, não acreditar em tudo o que encontramos. Quando é necessário fazer um trabalho de pesquisa na Internet, de forma autónoma, temos que ser nós a diferenciar a informação válida da que não serve. Isto porque não temos sempre ao nosso lado um professor para nos dizer o que é o certo ou o errado ( $\mathrm{R}_{11}$, feminino, 20 anos). 


\section{Discussão e conclusões}

Deste estudo depreende-se que os alunos universitários só fazem um uso quotidiano do telemóvel e do computador portátil no âmbito académico, pessoal e social. De momento não existem outros equipamentos móveis que, para as necessidades e preferências habituais os estudantes da educação superior, substituam os referidos ou integrem com uma aplicação expressiva. Justificam o seu interesse pela utilização destes dispositivos considerando as múltiplas e diversas atividades formativas que permitem desenvolver. Contudo, isto possibilitará assegurar o emprego de ambos os aparelhos no futuro campo profissional, quando exerçam como educadores sociais. Isto também poderia ser um indício do que, segundo Wang et al. (2012), noutros países é corrente quando apesar de toda a prática digital existente as experiências dos estudantes sobre o acesso às tecnologias móveis resultam limitadas.

Há que fazer fincapé em que os alunos da educação superior ainda diversificam pouco na utilização dos aparelhos móveis digitais, apresentando apenas dois equipamentos como habituais. Noutros estudos o telemóvel e o portátil são empregues essencialmente para a promoção de atividades específicas e/ou desenvolvimento de competências concretas. Por exemplo, Tsai et al. (2011) concluem que para os estudantes a aprendizagem com dispositivos móveis traz vantagens associadas ás práticas, como as de acesso à informação e a dinamização de processos ativos de aprendizagem. Por outro lado, neste trabalho descobre-se que os estudantes outorgam-lhe uma atribuição relevante aos dispositivos com possibilidades comunicativas, propriamente ditas que dipõem de conexão á internet em detrimento de outros que não contam com esta função ou onde resulta mais difícil esta aplicação.

Em contraste com outras investigações é possível concluir, a partir das descobertas deste estudo, que o padrão identificado sobre a praxis com os dispositivos móveis digitais não é caraterístico do grupo analisado (alunos universitários), nem do território em causa (Espanha). De modo que revela-se como uma manifestação globalizada e intergeracional. Veja-se o caso de outro trabalho, realizado num diferente país (Portugal), com uma população distinta (estudantes do ensino secundário), onde se conclui que o uso do computador por parte dos alunos se encontra bastante generalizado (Ricoy e Couto, 2009). Em Espanha, num outro estudo Agudo et al. (2012) determinam que o computador e a Internet são os recursos TIC mais utilizados entre os seniores. Em sentido similar, também outro trabalho 
argumenta que a aprendizagem móvel é de interesse para todos os estudantes sem barreiras geracionais (Wang et al., 2012).

Com esta investigação coloca-se em evidência as notórias possibilidades de acesso à rede das quais dispóem os estudantes universitários, juntamente com a licença de alguns recursos digitais. Para este fato provavelmente contribua o empenho que se verifica, em Espanha, principalmente a partir da participação institucional ao oferecer espaços equipados com diferentes dispositivos eletrónicos, acesso gratuito à Internet, e gratuidade nas licenças de alguns programas. Em consequência, os professores facilitam digitalmente materiais para o processo de aprendizagem em plataformas de teleformação e através de aplicações em linha, para partilhar e elaborar trabalhos em grupo, para intercambiar ideias, reflexões, etc. Tudo isto promove as relações, possibilita a democratização da informação e contribui através da Internet para a difusão de conteúdos e a igualdade de oportunidades. Muito embora, a sua contribuição para uma praxis inovadora continua a ser incipiente.

Com o estudo descobre-se que, outros fenómenos emergentes, como os associados à gamification, mais além de práticas lúdicas propriamente ditas, nos estudantes da educação superior ligam-se a motivação, curiosidade e prazer que deriva da atividade desenvolvida com aplicações digitais popularizadas e os produtos que lhes permitem gerar principalmente no plano informal (com a escuta de música, comunicação com colegas, participação em redes sociais e produção de fotografias). Esta tipologia de manifestações, no contexto universitário de momento, ainda que é de interesse, não impregna expressivamente o processo formativo.

As competências em TIC ressaltadas pelos alunos para utilização dos dispositivos digitais são as referidas a: resolução de problemas, procura de informação, habilidades comunicativas e autonomia pessoal. Há estudos que concluem que a procura de informação na Internet é uma das competências mais desenvolvidas na maioria dos estudantes (Buarki et al., 2011). Este aspeto é justificado essencialmente pelo facto de aqueles que têm acesso à informação contarem, em geral, com maiores possibilidades para a aprendizagem e desenvolvimento (como pessoas e cidadãos) do que os que não dispõem dessa facilidade (Gonçalves, 2011). Neste sentido a classe económica condicionaria a distribução das oportunidades favorecendo infelizmente a fenda digital.

Com menor ímpeto são consideradas pelos participantes outras competências para a utilização dos dispositivos móveis, na «sociedade do conhecimento», referidas a: prudência, partilha, abertura, motricidade, juízo crítico, criatividade, gestão de recursos, manejo técnico, persistência, 
autocontrole e o domínio do idioma inglês. Em particular, esta última deve ser considerada pelos docentes do ensino superior, no desenho e posterior implementação da planificação didática; assim como de forma preventiva desde a infância pelas famílias, oferecendo reforço nesta área, se fosse necessário ao par do facilitado na escola. Desta forma, estarão a capacitar aos jovens como cidadãos e futuros profissionais com as competências TIC demandadas, juntamente as requeridas pelo contexto sociocultural contemporâneo e os mercados do trabalho. No referido sentido, há que ter em conta que Buarki et al. (2011) provaram a existência de um desfasamento entre as competências que os alunos consideravam possuir e as exigências profissionais. Isto porque os estudantes avaliavam as suas capacidades associadas à fluidez digital num nível intermédio, concluindo que elas não satisfaziam os requisitos laborais do momento.

Neste estudo descobre-se que a competência de resolução de problemas é associada principalmente com as de procura de informação e a comunicativa, assim como em menor medida com a de abertura, autonomia e prudência. Cabe destacar que entre as mesmas produz-se uma conexão natural e complementaria muito interessante para acadar uma ótima formação integral. Gilleran (2006) evidenciava o conceito de comunidade virtual na qual os seus membros são capazes de encontrar de forma colaborativa soluções úteis pelo fato de partilharem experiências, desafios e problemas comuns. Registouse também uma conexão importante entre a procura de informação com a competência de abertura e autonomia, assim como com a de partilhar, a comunicativa, de motricidade e a de prudência. Estas habilidades são muito positivas em geral com o uso das TIC e, principalente, para evitar problemas importantes associados com a sobreexposição, o risco e a possível perda de privacidade na rede, e no futuro para perpetuar a formação contínua.

Fica patente a relevância que os participantes atribuem ao desenvolvimento da competência digital, considerando as múltiplas destrezas e habilidades que exige, em particular para o uso dos dispositivos móveis. Ultrapassando deste modo o simples manejo técnico dos equipamentos. Concordando com Area (2007) entende-se que os desafios que se colocam à alfabetização digital ultrapassam a simples visão mecanista relacionada com a aquisição de habilidades para o uso do hardware e software. Adicionalmente é notória a importância concedida a competências de nível superior, algumas delas relacionadas com processos cognitivos complexos e frequentemente associadas com a informação disponível digitalmente ou com dinâmicas sociais de comunicação ou partilha com outros colegas, sobre todo a partir da interação em comunidades virtuais. 
Do presente estudo decorre que os alunos universitários englobam, na conceção de competência digital, além das já referidas as capacidades cognitivas relacionadas com a obtenção, compreensão e reelaboração da informação; sem se esquecer, também das psicomotrizes e sociais. Póem de manifesto a conexão e importância que tem o domínio da competência digital para a aprendizagem ubícua através do uso dos dispositivos móveis, cujos benefícios atribuem fundamentalmente à versatilidade destes aparelhos e as aplicações e programas com os que permitem trabalhar, interacionar ou entreter-se em qualquer momento e lugar. Portanto estimam, mais além de algum obstáculo que experimentam, as suas enormes potencialidades e as possibilidades que lhes oferecem no plano académico, sociopessoal e no futuro para o exercício profissional.

\section{Limitações do estudo e prospetiva}

Tratando-se de um estudo qualitativo, indicar que os resultados e conclusões apresentadas poderiam transferir-se a outros contextos e considerar-se como referentes, ainda que sempre sob uma postura crítica e a partir da consideração da idiossincrasia de cada caso (Brown e Yule, 1998). No futuro poder-se-á ampliar a sua generalização completando-os com a perspetiva quantitativa desde a qual, como refletimos, se abordará também o referido projeto de investigação. De momento, o desvendado ajuda a incentivar a reflexão e constitui indicativos valiosos para que os docentes possam melhorar a articulação das atividades didáticas com o uso dos recursos digitais. Desta forma, podem contribuir para estimular, em maior medida, a inclusão destes últimos no processo formativo. Os padrões descobertos sobre a utilização dos dispositivos móveis digitais pelos estudantes universitários e as competências que consideram necessárias contribuiram para facilitar o trabalho dos professores, ao possibilitar um melhor conhecimento da realidade, permitindo-lhes planificar a praxis de forma mais sensata.

É previsível que a inclusão das TIC no processo formativo e a aquisição das referidas competências pelos alunos se translade da esfera académica à quotidiana e inversamente. Nesta linha, como percebem os estudantes é garantido, em boa medida, a transferência para o seu âmbito profissional futuro. Mais concretamente, no próprio caso estudado, é espectável que os educadores sociais façam o uso dos dispositivos móveis digitais a partir das competências TIC arrecadadas quando os participantes exerçam a atividade como educadores sociais. Por outra parte, é necessária uma formação ao longo da vida que possibilite a atualização exigida culturalmente, para o mundo 
María Carmen Ricoy y Maria João Valente da Silva Couto. Dispositivos móveis digitais e competências para a utilização na "sociedade do conhecimento"

do emprego e o exercício de uma cidadania ativa, relativamente aos atuais e futuros dispositivos tecnológicos.

\section{Referências bibliográficas}

Agudo, Susana et al. (2012), "Usos de las herramientas digitales entre las personas mayores", em Comunicar, vol. 20, n 39, Huelva: Grupo Comunicar Ediciones.

Almeida, Lucas e Freire, Gustavo Henrique (2012), “Ação de responsabilidade social para competências em informação”, em Perspectivas em Ciência da Informação, vol. 17, nº 3, Belo Horionte: Universidade Federal de Minas Gerais.

ANECA (2005), Libro Blanco. Título de Grado en Pedagogía y Educación Social, Madrid: Agencia Nacional de Evaluación de la Calidad y Acreditación.

Area, Manuel (2007), “A escola no labirinto tecnolóxico”, em Cid Fernández, Xose Manuel e Rodríguez Rodríguez, Xesús (coords.), A fenda dixital: e as súas implicacións educativas, Santiago de Compostela: Tórculo.

Area, Manuel (2010), “El proceso de integración y uso pedagógico de las TIC en los centros educativos. Un estudio de casos”, em Revista de Educación, n 352, Madrid: Ministerio de Educación, Cultura y Deporte.

Bergaud, Caroline et al. (2012), The E-Skills Manifesto, Brussels: European Schoolnet.

Brown, Gillian e Yule, Kaaawa (1998), Discourse analysis, Cambridge: University Press.

Buarki, Hanadi et al. (2011), "Lis Students' ICT Skills in Kuwait: Perspectives of Employers, Teaching Staff and Students", em US-China Education Review B, $\mathrm{n}^{\circ}$ 6, Illinois: David Publishing.

Calvani, Antonio et al. (2012), "Are Young Generations in Secondary School Digitally Competent? A Study on Italian Teenagers”, em Computers \& Education, vol. 58, n 2, Londres: Elsevier.

Cope, Bill e Kalantzis, Mary (2009), Ubiquitous Learning. Exploring the anywhere/anytime possibilities for learning in the age of digital media, Illinois: University of Illinois Press.

Cózar, Ramón e Roblizo, Manuel J. (2014), "La competencia digital en la formación de los futuros maestros: percepciones de los alumnos de los Grados de Maestro de la Facultad de Educación de Albacete", em Revista Latinoamericana de Tecnología Educativa, vol. 12, no 2. Espanha: Universidad de Extremadura.

Duart, Josep María (2011), “La red en los procesos de enseñanza de la Universidad”, em Comunicar, no 37, Huelva: Grupo Comunicar.

García-Lastra, Marta (2013), "Educar en la sociedad contemporánea. Hacia un nuevo escenario educativo", em Convergencia, n 62, México: Universidad Autónoma del Estado de México.

Gilleran, Anne (2006), "Práticas inovadoras em escolas europeias", em Sancho, Juana Maria e Hernández, Fernando (org.), Tecnologias para transformar a educação, Porto Alegre: ARTMED.

Gómez Gonzalvo, Fernando (2014), "Educational innovation through ICTs in the university setting. What do students think of these practices?", em Revista de Universidad y Sociedad del Conocimiento, vol. 11, n 1, Barcelona: Universitat Oberta de Catalunya.

Gonçalves, Elisabete (2011), "Sociedade da informação e reestruturação produtiva: crítica à dimensão utilitarista do conhecimento", em Transinformação, vol. 23, nº 3, Campinas: Pontifícia Universidade Católica de Campinas. 
Convergencia Revista de Ciencias Sociales, núm. 70, 2016, Universidad Autónoma del Estado de México

Gvaramadze, Irakli (2012), "Developing Generic Competences in Online Virtual Education Programmes at the University of Deusto”, em Campus-Wide Information Systems, vol. 29, $\mathrm{n}^{\circ}$ 1, Bingley: Emerald.

Hargreaves, Andy (1998), Os Professores em Tempos de Mudança. O Trabalho e a Cultura dos Professores na Idade Pós-Moderna, Lisboa: McGraw-Hill.

Hernández, Roberto et al. (2006), Metodología de la investigación, México: McGraw-Hill.

Kobus, Martijn et al. (2013), "Ownership versus on-campus use of mobile IT devices by university students”, em Computers \& Education, vol. 68, Londres: Elsevier.

Livingstone, Sonia et al. (2011), Risks and safety on the Internet: The perspective of European children. Full Findings, Londres: EU Kids Online.

Moran, José Manuel (2010), "Ensino e Aprendizagem Inovadores com Tecnologias Audiovisuais e Telemáticas”, em Moran, José Manuel, Masetto, Marcos e Behrens, Marilda Aparecida (eds.), Novas Tecnologias e Mediação Pedagógica, Campinas: Papirus.

Raynal, Françoise e Rieunier, Alain (1998), Pédagogie: dictionaire des conceptes clés, Paris: ESF éditeur.

Ricoy, María Carmen e Couto, Maria João (2009), "As tecnologias da informação e comunicação como recursos no Ensino Secundário: um estudo de caso”, em Revista Lusófona de Educação, vol.14, n 14 , Lisboa: Universidade Lusófona de Humanidades e Tecnologias.

Said-Hung, Elias (2012), "O uso das TIC por docentes de cenários de ensino superior na Colômbia”, em Convergencia, n 58, Cidade do México: Universidad Autónoma del Estado de México.

Sánchez-Antolín, Pablo et al. (2014), "Formación continua y competencia digital docente: El caso de la Comunidad de Madrid”, em Revista Iberoamericana de Educación, n 65 , 91-110. Espanha: OEI.

Tait, Alan (2013), "Distance and E-Learning, Social Justice, and Development: The Relevance of Capability Approaches to the Mission of Open Universities", em The International Review of Research in Open and Distance Learning, vol. 14, n ${ }^{\circ} 4$, Athabasca: Athabasca University.

Tierney, Patrick (2012), "A Qualitative Analysis Framework Using Natural Language Processing and Graph Theory", em The International Review of Research in Open and Distance Learning, vol. 13, $\mathrm{n}^{\circ}$ 5, Athabasca: Athabasca University.

Tsai, Pei-Shan et al. (2011), "College students' conceptions of context-aware ubiquitous learning: A phenomenographic analysis", em The Internet and Higher Education, vol. 14, $\mathrm{n}^{\circ} 3$, Londres: Elsevier.

Villavicencio, Daniel et al. (2012), "Indicadores y asimetrías sobre la Sociedad Basada en el Conocimiento en América Latina”, em Perfiles Latinoamericanos, n 40, Tlalpan: Facultad Latinoamericana de Ciencias Sociales.

Wang, RuoLan et al. (2012), "Developing digital fluency through ubiquitous mobile devices: Findings from a small-scale study”, em Computers \& Education, vol. 58, n 1 , Londres: Elsevier.

Yin, Robert (2005), Estudos de Caso. Planejamento e método, Porto Alegre: Bookman.

Yin, Robert (2009), Case Study Research, Design and Method, Londres: Sage. 
María Carmen Ricoy y Maria João Valente da Silva Couto. Dispositivos móveis digitais e competências para a utilização na "sociedade do conhecimento"

\section{Anexo}

\section{Figura 1}

\section{Dispositivos móveis utilizados pelos alunos}

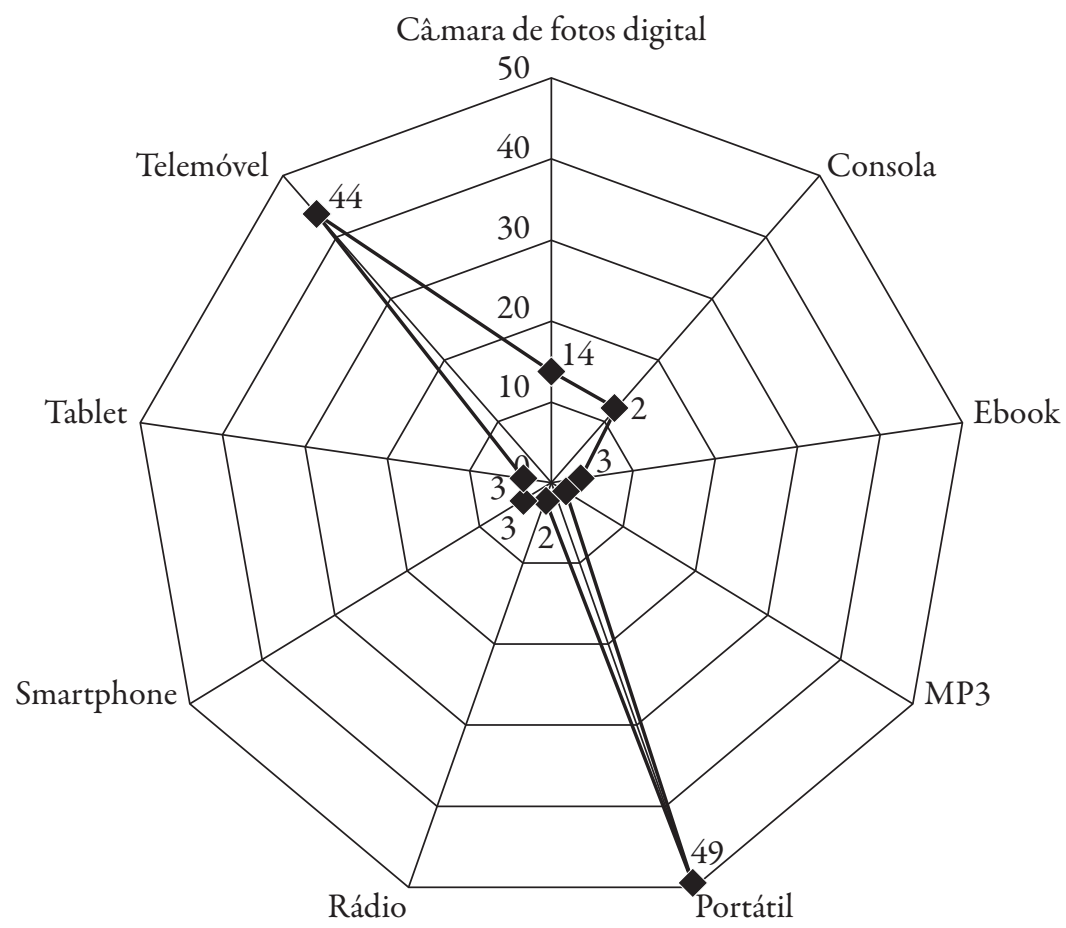

Fonte: Elaborado pelas autoras partindo dos dados da pesquisa. 
Figura 2

\section{Competências para a utilização dos dispositivos}

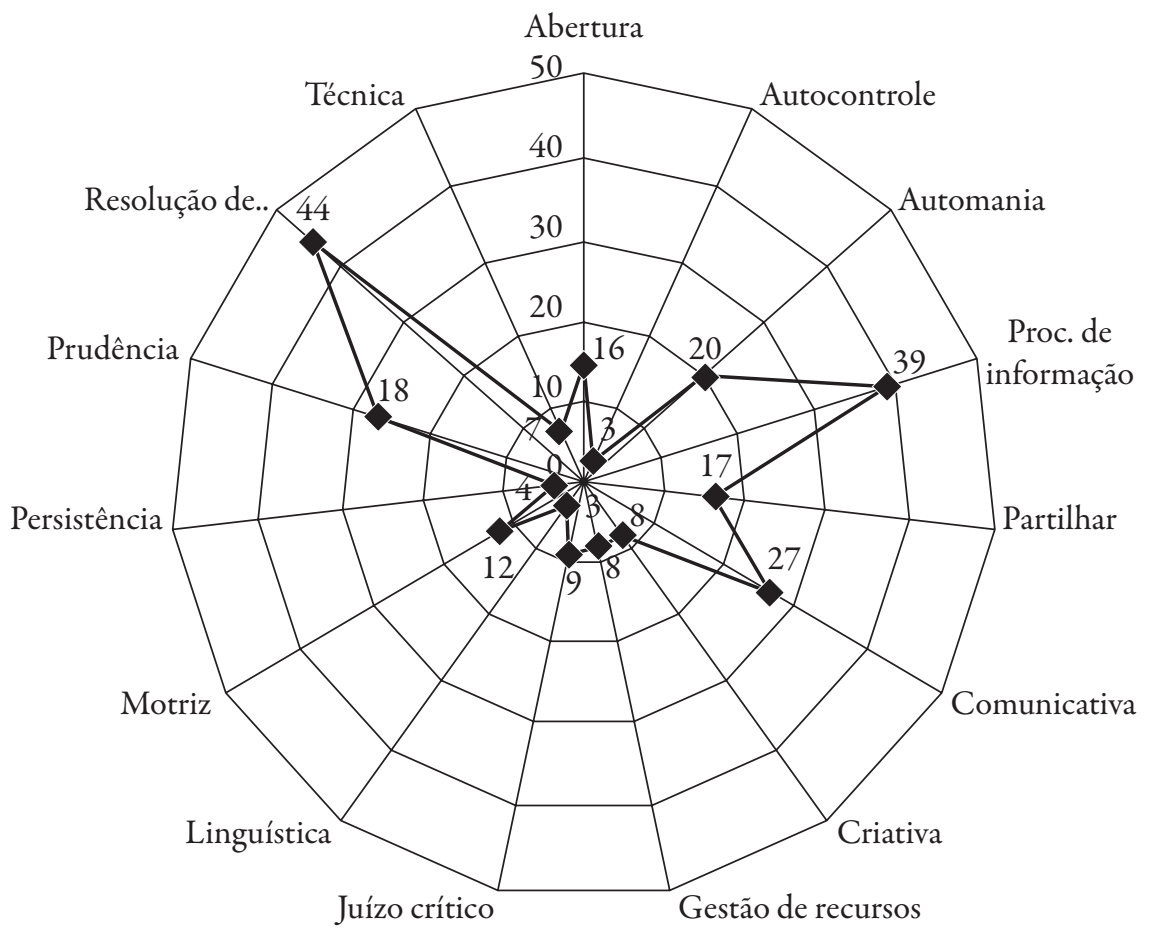

Fonte: Elaborado pelas autoras partindo dos dados da pesquisa. 


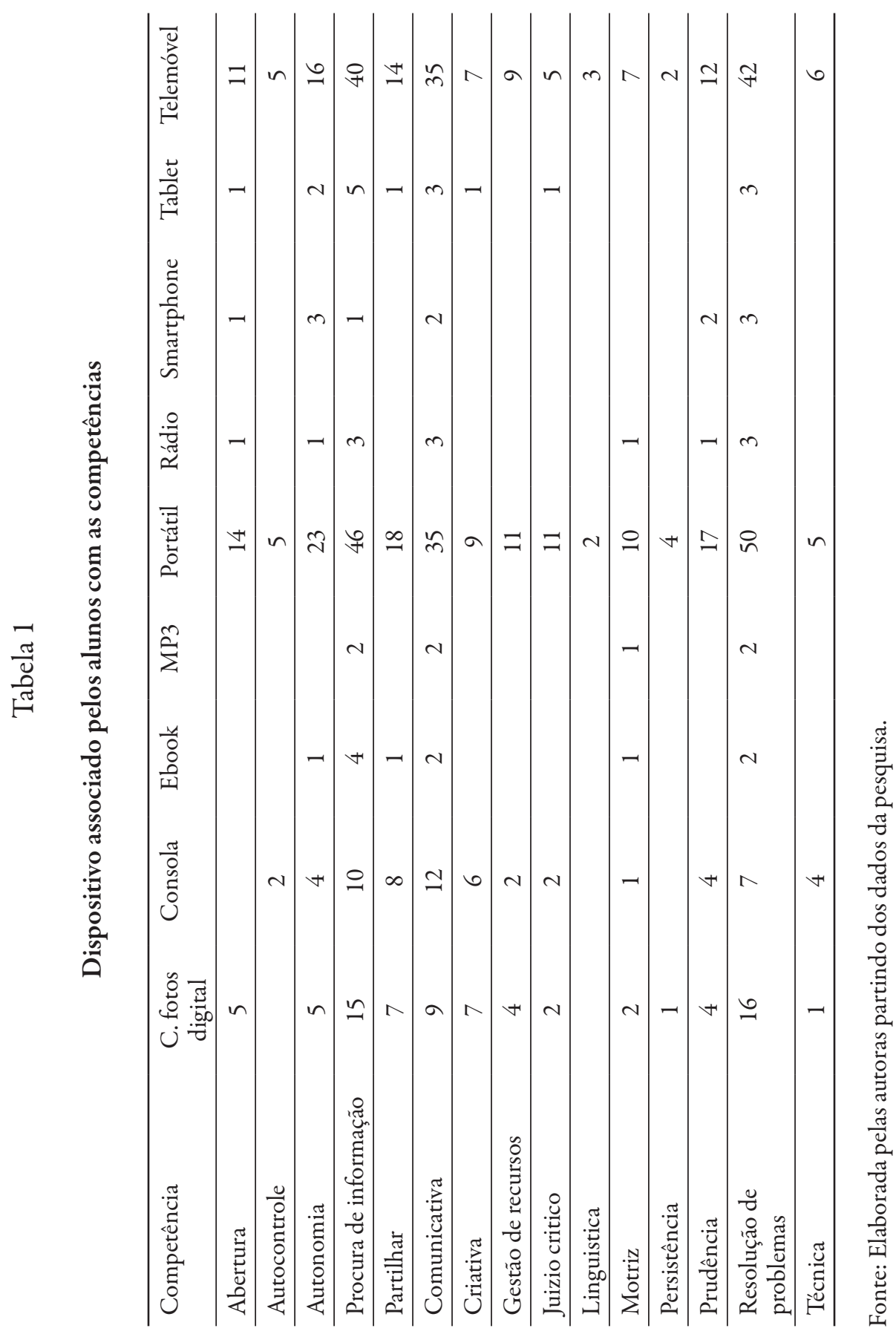




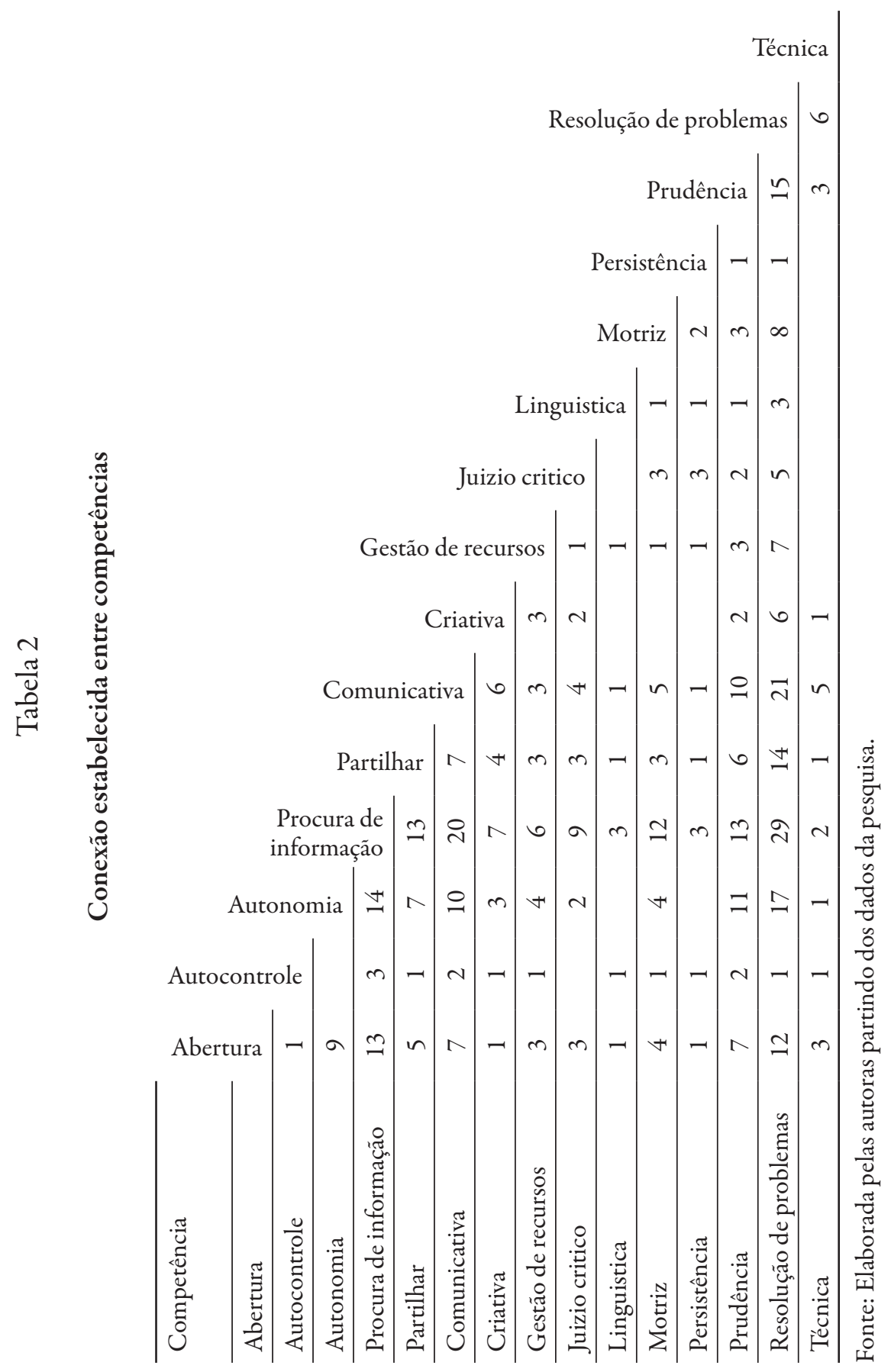


María Carmen Ricoy. Doutora em Filosofia e Ciências da Educação (2001). É Professora Titular de Universidade na Faculdade de Ciências da Educação, Universidade de Vigo (Espanha). Nas suas linhas de investigação aborda as tecnologias da informação e comunicação, redes sociais e formação, a educação social e a avaliação de programas socioeducativos. Entre as suas publicações podem referir-se: "Contribuciones y controversias que genera el uso de las TIC en la educación superior: un estudio de caso”, em Revista de Educación, núm. 360, Madrid: Ministério da Educação, Cultura e Desporto Espanhol (2013); "Competencias necesarias para la utilización de las principales herramientas de internet en la educación", em Revista de Educación, núm. 356, Madrid: Ministério da Educação, Cultura e Desporto Espanhol (2011).

Maria João Valente da Silva Couto. Licenciada em Matemática ramo educacional. Atualmente é professora de mestrado na Faculdade de Ciências da Educação da Universidade de Vigo (Espanha) e doutoranda no programa de educação em contextos formais e não formais, tendo contado com uma bolsa da Fundação de Ciência e Tecnologia (Portugal). As suas áreas de investigação são as tecnologias da informação e comunicação na educação e os ambientes de aprendizagem pessoal. Entre as suas publicações podem referirse: Ricoy, María Carmen, Feliz, Tiberio e Couto, Maria João, "The digital divide among university freshmen.", em TOJET: The Turkish Online Journal of Educational Technology, vol. 12, núm. 2, Sakarya: Sakarya University (2013); Ricoy, María Carmen e Couto, Maria João, "El acercamiento al contexto profesional como móvil para indagar sobre las TIC: un estudio cualitativo", em Revista Complutense de Educación, vol. 19, núm. 2, Madrid: Universidad Complutense (2012).

Recepção: 15 de fevereiro de 2014.

Aceitação: 25 de março de 2015. 
